Vol. 1 No. 1, Feb 2021, hlm. $31-38$

DOI: https://doi.org/10.33330/.v1i1.1026

Available online at http://jurnal.stmikroyal.ac.id/index.php/jutsi

\title{
PEMBUATAN MEDIA EDUKASI INTERAKTIF PEMBAGIAN HARTA WARISAN MENURUT ISLAM BERBASIS MULTIMEDIA
}

\author{
Anisa Bahari ${ }^{1}$, Havid Syafwan ${ }^{2 *}$, Sri Rezki Maulina Azmi ${ }^{3}$ \\ ${ }^{1}$ Mahasiswa Prodi Manajemen Informatika, STMIK Royal \\ ${ }^{2}$ Prodi Manajemen Informatika, STMIK Royal \\ ${ }^{3}$ Prodi Sistem Informasi, STMIK Royal \\ *email: havid_syafwan@yahoo.com
}

\begin{abstract}
In line with the development of the knowledge and technology are too fast, so it's effect on increasing the media and other learning resources that are more practical. multimedia can be used as a choice of learning media to support interest because it's more effective and practical to use. Based on observations on the MAS Al Jam'iyatul Washliyah Kisaran, the method or way the teacher teaches is still manual that is using books and then the teacher explains and is recorded directly by his students. This method seems monotonous and unappealing. So created an interactive educational media for the distribution of inheritance according to Islam based on multimedia using the Adobe Flash CS6 application. This learning media will be useful for providing information about the distribution of inheritance according to Islam to students and teachers at MAS Al Jam'iyatul Washliyah Kisaran. This application consist of various multimedia elements such as text, picture, sound, videos and other objects. So that this application will be more interesting and more effective to use.
\end{abstract}

Keywords: Creating; Division of Inheritance; Adobe Flash CS6; Multimedia

\begin{abstract}
Abstrak: Sejalan dengan pertumbuhan ilmu pengetahuan dan teknologi yang begitu pesat, hingga berpengaruh pada bertambahnya media dan sumber belajar lainnya yang lebih praktis, multimedia dapat dijadikan salah satu pilihan media pembelajaran untuk menunjang ketertarikan karena lebih efektif dan praktis untuk dipergunakan. Berdasarkan hasil observasi pada MAS Al Jam'iyatul WashliyahKisaran, metode atau cara guru mengajarkan masih manual yaitu menggunakan buku kemudian guru menerangkan dan dicatat langsung oleh muridnya. Metode ini terkesan monoton dan tidak menarik.Sehingga dibuat suatu Media Edukasi Interaktif Pembagian Harta Warisan Menurut Islam Berbasis Multimedia menggunakan aplikasi Adobe Flash CS6. Media pembelajaran ini akan berguna untuk memberikan informasi-informasi mengenai pembagian harta warisan menurut Islam kepada siswa/i serta guru di MAS Al Jam'iyatul Washliyah Kisaran. Aplikasi ini terdiri dari berbagai elemen-elemen multimedia seperti teks, gambar, suara, video dan objek-objek lainnya. Sehingga aplikasi ini akan lebih menarik dan lebih efektif untuk digunakan.
\end{abstract}

Kata kunci: Pembuatan; Pembagian Warisan;Adobe Flash CS6;Multimedia 
Vol. 1 No. 1, Feb 2021, hlm. 31 - 38

DOI: https://doi.org/10.33330/.v1i1.1026

Available online at http://jurnal.stmikroyal.ac.id/index.php/jutsi

\section{PENDAHULUAN}

Harta warisan adalah harta peninggalan yang ditinggalkan oleh pewaris kepada ahli warisnya.Mawaris adalah bentuk jamak dari kata miiraas yang artinya harta yang ditinggalkan oleh seseorang yang telah meninggal dunia baik laki-laki maupun perempuankepada ahli warisnya yang berhak memperoleh harta warisan.Dasar seseorang untuk mewarisi atau untuk memperoleh warisan menurut Al-Quran ialah karena hubungan keluarga, hubungan pernikahan atau perkawinan dan hubungan wala' atau kerabat.

Hukum waris merupakan hukum yang mengatur pembagian serta pemindahan harta peninggalan atau pusaka seseorang yang telah meninggal dunia yang kemudian diserahkan kepada ahli warisnya yang berhak secara adil dan merata sesuai dengan kaidah-kaidah fiqih yang berlaku.Ada beberapa istilah penamaan hukum kewarisan dalam Islam seperti Faraid, Fiqih Mawaris, dan Humkal-Waris yang membedakan penamaan hukum-hukum tersebut adalah arah yang dijadikan titik utama dalam pembahasan.

Lingkungan pendidikan saat ini termasuk salah satu konsumen atau pengguna dari teknologi informasi yang terus meningkat dengan pesat dari waktu ke waktu.Perkembangan ilmu dan teknologi berpengaruh pada bertambahnya media dan sumber belajar yang beraneka ragam dan dapat menunjang berbagai macam kebutuhan belajar-mengajar, multimedia dapat dijadikan sebagai pilihan media pembelajaran untuk menunjang ketertarikan siswa/i karena lebih efektif dan praktis untuk dipergunakan.

Multimedia merupakan sekumpulan perangkat lunak yang terdiri dari animasi, grafik, audio dan visual. Pengguna dapat mengoperasikan multimedia sesuai dengan kebutuhan yang diperlukan karena multimedia dapat dilengkapi dengan alat bantu dan koneksi[1]. Multimedia adalah pemanfaatan suatu sarana atau media untuk menampilkan objek-objek dari berbagai elemen seperti teks, gambar, audio, vidio dan animasi dengan menggunakan alat bantu dan koneksi sehingga pemakai atau user dapat menjalankan navigasi, melakukan tindakan atau aksi, berkreasi dan saling bertukar informasi. Multimedia bisa digunakan sebagai wadah atau media untuk mengedukasi dan memberikan informasi baik untuk bahan pengajaran atau pun untuk umum [2].

Berdasarkan hasil observasi pada MAS Al Jam'iyatul Washliyah Kisaran, metode atau cara guru mengajarkan masih manual yaitu menggunakan buku lalu kemudian guru menerangkan dan dicatat langsung oleh muridnya. Dibandingkan dengan buku yang lebih monoton, multimedia memiliki tampilan yang lebih atraktif dan lebih menyenangkan untuk digunakan dalam proses belajar mengajar dengan menggabungkan link dan tool yang memungkinkan pemakai melakukan navigasi, berintraksi, berkreasi dan berkomunikasi. Multimedia dapat menyampaikan isi pelajaran dengan modern dan berkesan sehingga menghasilkan proses belajar mengajar yang lebih memuaskan.

\section{METODE}

\section{Hukum Warisan}

Dalam buku yang ditulis oleh Hasanudin yang berjudul "Fiqh Mawaris Problematika dan Solusi", yang menjadi dasar-dasar hukum ilmu mawaris ada tiga 
Vol. 1 No. 1, Feb 2021, hlm. 31 - 38

DOI: https://doi.org/10.33330/.v1i1.1026

Available online at http://jurnal.stmikroyal.ac.id/index.php/jutsi

diantaranya Al-Qur'an, Hadis, Ijma' dan Ijtihad. Al-qur'an telah menjelaskannya secara jelas dan tegas mengenai hukum waris dalam surat an-Nisa' ayat 7-12, 176 dan beberapa ayat yang lain. Sumber hukum yang kedua setelah Al-Qur'an ialah hadis, Hadis memberikan penjelasan-penjelasan yang belum diterangkan di dalam Al-Qur'an mengenai pelaksanaan mawaris. Hasil pemutusan suatu perkara yang tidak dibahas secara terperinci di dalam Al-Qur'an dan hadis disebut dengan ijma'dan Ijtihad, hal ini dapat dilakukan oleh para ulama dengan memakai akal sehat dan juga pertimbangan yang matang.

\section{Syarat dan Rukun Waris}

Rukun merupakan hal atau pekerjaan yang harus dilakukan sebelum pekerjaan pokok dilaksanakan. Jika hal yang menjadi rukun itu tidak ada maka pekerjaan pokok tidak akan bisa dilaksanakan. Adapun sayarat merupakan suatu ketentuan yang harus ada pada saat pekerjaan pokok dilaksanakan. Rukun waris ada 3 diantaranya yaitu: (1) Muwarris adalah orang yang mewariskan dan telah meninggal dunia, muwarris harus benar-benar meninggal secara hakiki atau meninggal hukmi., (2) Waris, syarat orang yang akan mewarisi harta dari orang yang meninggal adalah ahli waris benar-benar hidup setelah muwarris dinyatakan meninggal dan ia berhak memperoleh warisan., (3) Mawrus adalah harta yang ditinggal oleh muwarris dan belum dibagikan sebelum ia meninggal dengan jalan hibah.

\section{Definisi Multimedia}

Menurut M. Suyanto dalam bukunya yang berjudul "Multimedia alat untuk meningkatkan keunggulan bersaing", multimedia merupakan gabungan dari komputer dan vidio. Secara umum multimedia ialah campuran dari 3 elemen yang terdiri dari audio, gambar dan text. Multimedia juga dapat dikatan sebagai gabungan dari 2 media diantaranya yaitu input (masukan) dan output (keluaran) dari data, media ini dapat berupa audio, animasi, video, teks, grafik dan gambar atau multimedia adalah alat yang dapat menghasilkan suatu presentasi dan tampilan yang dinamis dan interaktif yang mengkombinasikan objek dari berbagai elemen seperti teks, grafik, animasi, audio dan gambar video [3].

Pengertian yang lain tentang multimedia adalah penggunaan sistem komputer dalam menciptakan serta menyatukan audio, video, animasi, text, dan grafik dengan cara menyatukan link dan tool yang memungkinkan pemakai menjalankan navigasi, berinteraksi, berkreasi dan berkomunikasi [4].

\section{Objek Multimedia}

Multimedia memiliki enam komponen didalamnya, komponenkomponentersebut adalah [5] : (1) Teks, Teks Suatu objek yang paling sederhana untuk disimpan dan dikendalikan dalam multimedia ialah teks.Teks bisa dibentuk menjadi sebuah kata, kalimat ataupun sebuah paragraf dalam multimedia.Kebutuhan teks tergantung pada seberapa banyak penggunaan teks itu sendiri.Contohnya ketika membuat sebuah game, maka teks yang digunakan dan dibutuhkan cenderung lebih sedikit dibandingkan ketika membuat sebuah ensiklopedia yang tentu saja membutuhkan banyak teks dalam pembuatannya. Teks memiliki beberapa jenis diantaranya ialah teks cetak, teks hasil scan, teks elektronis, dan hypertext., (2) Grafis, 
Vol. 1 No. 1, Feb 2021, hlm. 31 - 38

DOI: https://doi.org/10.33330/.v1i1.1026

Available online at http://jurnal.stmikroyal.ac.id/index.php/jutsi

Garis seringkali muncul sebagai latar belakang suatu teks untuk memberikan kesan visualisasi atau gambaran tertentu yang akan mempercantik tampilan teks. Gambar dan teks dapat dipadukan menjadi sebuah ikon sehingga menunjukan berbagai pilihan yang dapat dipilih.Gambar juga bisa diatur agar dapat muncul untuk menggantikan teks., (3) Suara, Suaradalam pembuatan multimedia ada bermacam-macam jenis format suara yang bisa dipakai, jenis-jenisnya yaituwave form audio, aiff, dat, ibk, mod, rmi,sbi, snd, voc, au, MIDI sound track, compact disc audio, dan MP3 file., (4) Video, Video memberikan banyak kegunaan untuk melengkapi projek multimedia agar terlihat lebih menarik. Ada empat macam vidio yang bisa dijadikan objek link pada multimedia yaitu live video feeds, videotape, videodisc, dan digital video., (5) Animasi, Animasi adalah rangkaian dari beberapa objek yang diatur agar mengikuti alur sehingga menciptkan objek yang bergerak pada layar.Jenis animasi itu sendiri ada sembilan macam, yaitu animasi sel, animasi frame, animasi sprite, animasi lintasan, animasi spline, animasi vektor, animasi karakter, animasi computational, dan morphing., (6) Software dan Data, Multimedia memiliki konsep dimana berbagai dokumen dan dataset dapat diakses melalui suatu link.Ketika pengguna mengklik satu link kesuatu dokumen word processor, seperti file, doc, di Microsoft Word misalnya, maka komputer akan secara otomatis meluncurkan aplikasi perangkat lunak dan menggunakannya untuk menampilkan dokumen yang dimaksud. Begitu pula, sebuah linkkesebuah file .xls di Excel untuk menampilkan spreadsheet tersebut.

\section{Struktur Navigasi}

Struktur navigasi adalah alat bantu yang dapat digunakan dalam merancang aliran aplikasi multimedia. Struktur-struktur tersebut yaitu struktur linier, stuktur menu, struktur hirarki dan struktur kombinasi.

\section{Struktur Linier}

Struktur linier dapat dikatakan sebagai salah satu struktur yang paling sederhana karena hanya menggunakan satu alur saja.Struktur ini menampilkan program multimedia satu per satu secara bergantian.Dapat menampilkan halaman selanjutnya atau halaman sebelumnya. Rangka dari stuktur linier dapat dilihat pada Gambar 1.

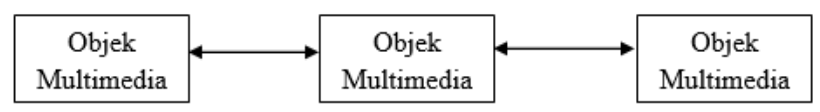

Gambar 1.Rangka Struktur Linier

\section{Struktur Hirarki}

Struktur hirarki adalah struktur yang memiliki cabang-cabang sehingga bentuknya menyerupai pohon.Struktur ini memiliki sebuah menu utama dengan banyak pilihan menu pendukung. Struktur ini tidak dibatasi dalam jumlah menu atau pun submenu yang dapat dimiliki. Rangka dari stuktur hirarki dapat dilihat pada Gambar 2. 
Vol. 1 No. 1, Feb 2021, hlm. $31-38$

DOI: https://doi.org/10.33330/.v1i1.1026

Available online at http://jurnal.stmikroyal.ac.id/index.php/jutsi

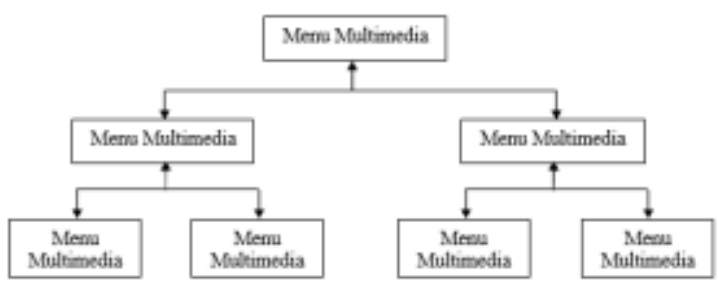

Gambar 2. Rangka Struktur Hirarki

\section{Struktur Jaringan}

Struktur jaringan dapat dikatakan sebagai alur yang paling kompleks karena memiliki banyak objek dalam setiap alurnya. Rangka dari stuktur jaringan dapat dilihat pada Gambar 3.

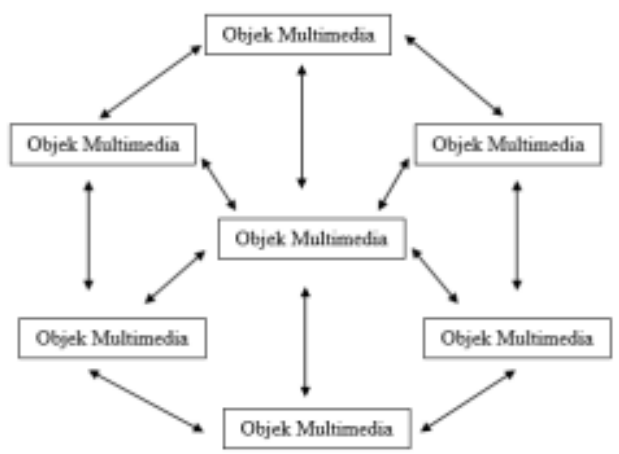

Gambar 3. Rangka StrukturJaringan

\section{Struktur Kombinasi}

Struktur ini merupakan gabungan dari struktur linier dan struktur hirarki, dimana struktur ini menyediakan banyak pilihan-pilihan menu di dalamnya. Rangka dari stuktur kombinasi dapat dilihat pada Gambar 4.

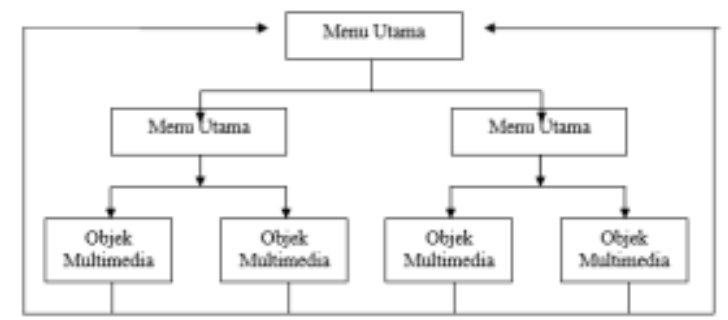

Gambar 4. Struktur Kombinasi

\section{Adobe Flash CS6}

Adobe Flash CS6 adalah perangkat lunak yang dirancang khusus oleh Adobe serta program aplikasi standar authoring tool. Adobe Flash CS6 biasanya dipakai untuk merancang sebuah animasi serta bitmap yang dipergunakan untuk membangunsitus web yang interaktif dan juga aktif. Adobe Flash CS6 mempunyai banyak fitur yang sangat berguna sehingga proses perancangan animasi dapat dilakukan dengan lebih mudah dan lebih menarik bagi para animator. 
Vol. 1 No. 1, Feb 2021, hlm. $31-38$

DOI: https://doi.org/10.33330/.v1i1.1026

Available online at http://jurnal.stmikroyal.ac.id/index.php/jutsi

\section{HASIL DAN PEMBAHASAN}

\section{Perancangan aplikasi media pembelajaran}

Pada pembuatan media pembelajaran ini terdapat dua proses, yakni proses pengumpulan bahan atau materi dan juga proses editing dengan menggunakan beberapa perangkat lunak [6].

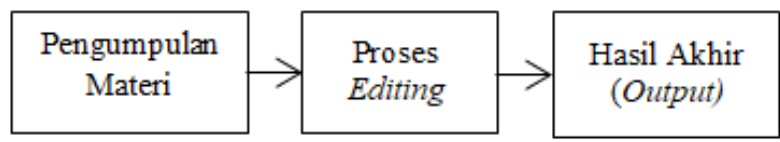

Gambar 5. Proses Produksi Aplikasi

Pengumpulan Materi yang dikumpulkan berupa beberapa gambar-gambar yang dibutuhkan, beberapa audio seperti rekaman suara, audio backsound dan juga materimateri pembelajaran pembagian harta warisan menurut Islam. Dalam melakukan proses editing tidak hanya memakai Adobe Flash CS6 saja, tetapi juga memakai Adobe Photoshop CS6.

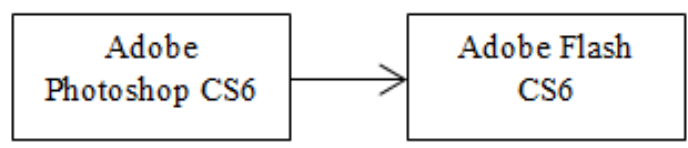

Gambar 6. Proses Editing

\section{Uji Coba Program}

Uji program dilakukan untuk memastikan apakah setiap bagian atau komponen program dapat berjalan dengan baik atau tidak. Uji coba dilakukan dengan cara memilih menu "control - test scene (ctrl+enter)". Berikut tampilan program ketika dijalankan:

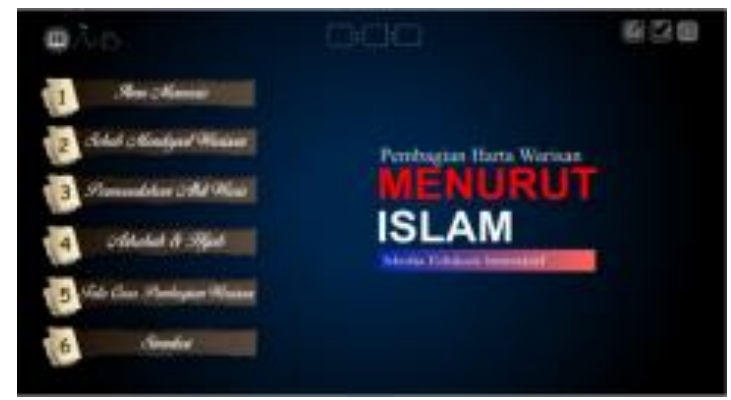

Gambar 7.Tampilan Halaman Edukasi

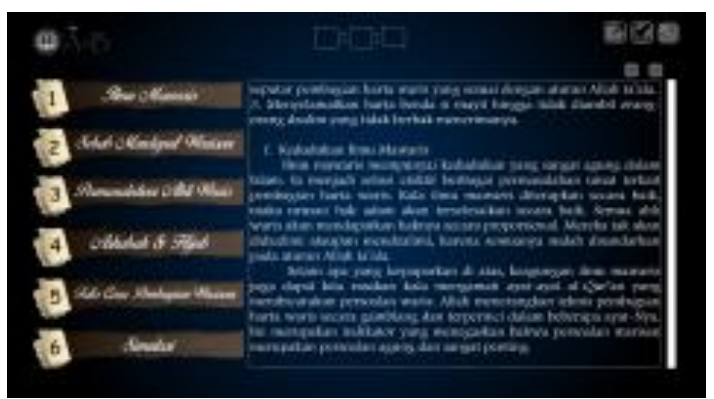

Gambar 8.Tampilan Halaman Materi 
Vol. 1 No. 1, Feb 2021, hlm. 31 - 38

DOI: https://doi.org/10.33330/.v1i1.1026

Available online at http://jurnal.stmikroyal.ac.id/index.php/jutsi

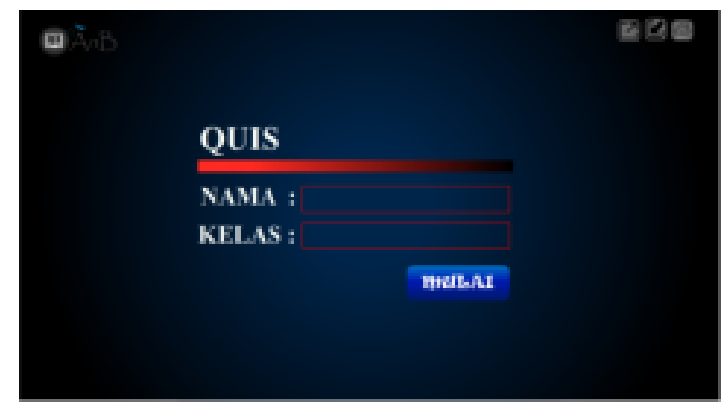

Gambar 9.Tampilan Halaman Awal Quis

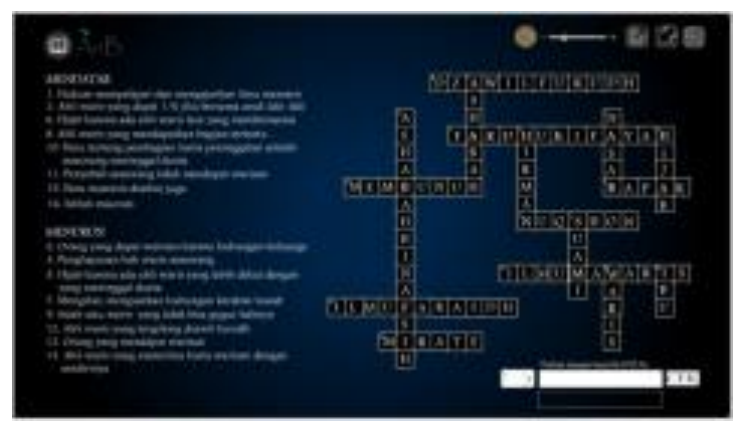

Gambar 10.Tampilan Halaman Games

\section{Pembahasan}

Pada perancangan media pembelajaran berbasis multimedia ini memiliki pembahasan mengenai pembuatan program yang mana program ini masih memiliki kelebihan dan kekurangannya masing-masing.

Adapun kelebihan dari perancangan program aplikasi media pembelajaran berbasis multimedia ini adalah: (a) Dengan adanya perancangan program pembelajaran ini dapat mempermudah proses pembelajaran serta memudahkan proses penyampaian materi dengan cara yang lebih menyenangkan. Media pembelajaran ini di rancang sedemikian rupa agar terlihat lebih menarik. Program pembelajaran ini sudah memuat audio dan vidio mengenai cara-cara menghitung warisan secara Islam., (b) Karena sifatnya digital, jadi lebih mudah dalam pendistribusiannya sehingga program ini dapat dicopy., (c) Program pembelajaran ini sangat mudah untuk dipakai dan sangat mudah dimengerti.

Adapun kekurangan yang dimiliki oleh media pembelajaran berbasis multimedia ini adalah sebagai berikut: (a) Untuk pengembangan isi materi maupun bentuk media pembelajaran ini sendiri kedepannya masih memerlukan pemroduksian ulang., (b) Program ini hanya menampilkan pembahasan secara umum tidak menampilkan pembahasan materi secara spesifik., (c) Untuk simulasi kalkulator penghitung warisan secara Islam masih harus terkoneksi dengan internet. 
Vol. 1 No. 1, Feb 2021, hlm. $31-38$

DOI: https://doi.org/10.33330/.v1i1.1026

Available online at http://jurnal.stmikroyal.ac.id/index.php/jutsi

\section{SIMPULAN}

Berdasarkan hasil penelitian dan perancangan media edukasi interaktif berbasis multimedia menggunakan aplikasi Adobe Flash CS6 pada materi pembelajaran pembagian harta warisan menurut Islam, maka diperoleh kesimpulan bahwa dengan adanya media pembelajaran pembagian harta warisan menurut Islam yang memuat elemen-elemen multimedia seperti audiodan vidio ini dapat memudahkan penyampaian isi materi dan lebih menarik minat dan perhatian siswa/i serta mudah digunakan dalam proses belajar mengajar.

\section{DAFTAR PUSTAKA}

[1] H. Syafwan, R. Afriyanti, J. Imam, and B. No, "Perancangan Media Interaktif Untuk Pembelajaran Rantai," J. Manaj. Inform. dan Tek. Komput. Peranc., vol. 2, no. 1, pp. 39-44, 2017.

[2] H. Syafwan et al., "Perancangan Media Pembelajaran Interaktif Tata Cara Shalat Jenazah Berbasis Multimedia," J. Manaj. Inform. dan Tek. Komput. Vol., vol. 2, no. 2, pp. 118-122, 2017.

[3] A. Budiarti, J. Handhika, and S. Kartikawati, "Pengaruh Model Discovery Learning Dengan Pendekatan Scientific Berbasis E-Book Pada Materi Rangkaian Induktor Terhadap Hasil Belajar Siswa," Jupiter (Jurnal Pendidik. Tek. Elektro), vol. 2, no. 2, p. 21, 2017, doi: 10.25273/jupiter.v2i2.1795.

[4] U. I. Arsyah and A. Munandar, "Perancangan media pembelajaran lagu-lagu daerah pada yayasan pendidikan Al-Mawaddah Teladan Kisaran berbasis multimedia," J. Manaj. Inform. dan Tek. Komput., vol. No. 2, no. No. 2, pp. 127$132,2017$.

[5] K. Firmantoro, A. Anton, and E. R. Nainggolan, "Animasi Interaktif Pengenalan Hewan Untuk Pendidikan Anak Usia Dini,” None, vol. 13, no. 2, pp. 14-22, 2016, doi: 10.33480/techno.v13i2.202.

[6] D. Tarigan and S. Siagian, "Pengembangan Media Pembelajaran Interaktif Pada Pembelajaran Ekonomi," J. Teknol. Inf. Komun. Dalam Pendidik., vol. 2, no. 2, pp. 187-200, 2015, doi: 10.24114/jtikp.v2i2.3295. 